\title{
Primary Students’ Book Club Participation
}

\author{
K. DARA HILL \\ University of Michigan-Dearborn
}

\begin{abstract}
This study is an examination of first grade students' participation in Book Club at a high achieving, high poverty urban primary school in Detroit. In spite of the school's high performing record, teachers are constrained by having to adhere closely to the pacing guide and the exclusive use of curriculum literature to preserve the school's high achieving status. Irrelevant curriculum materials surrounding the themes "Keep Trying" and "Being Afraid" led to a teacher and researcher collaboration to use relatable supplemental texts. An examination of peer-led discussion groups demonstrated deep comprehension and students' ability to mediate personal connections and multiple perspectives.
\end{abstract}

\section{Introduction}

This study took place in a high achieving, high poverty primary school in Detroit-pseudonym "Gladstone School". In spite of challenges that ordinarily underlie low student achievement for schools under similar circumstances, Gladstone School sustains a climate of trust, strong administrative support, and highly qualified teachers. In this sense, Gladstone School represents the minority of successful Detroit Public Schools. The neighborhood is characterized by high levels of joblessness, residential mobility, and limited economic opportunity, which suggest drug activity and related violence, similar to the high poverty Chicago enclave that Wilson (1996) describes. High achievement at Gladstone School is indicated by criterion-referenced tests in grades three through five, in which scores surpass state averages in Michigan. However, the district struggles to raise criterion-referenced test scores and retain students. Low performance and exodus of students to schools in neighboring suburbs have led to many school closures.

\section{Background}

Early literacy policy is informed by the National Council of Teachers of English and International Reading Association standards. The state calls for balanced literacy practices that are relevant to students' experiences. Moreover, the state regulated curriculum, known in Michigan as the Grade Level Content Expectations (GLCE), informs content on the statewide criterion-referenced tests. NCLB, however, has posed consequences for literacy policy and teacher autonomy at the local level. 70 percent of students in each Michigan school must achieve a passing score on the statewide tests to achieve Adequate Yearly Progress (AYP). Schools meeting AYP usually have autonomy to employ the balanced literacy practices intended by the state and national regulated curriculum. Schools not meeting AYP must adhere to literacy policy informed by skillsbased curriculum at the district level, and they are monitored closely for performance and slated for closure or administrative and faculty changes if they do not improve performance levels. 
In spite of Gladstone School's longstanding record of sustaining AYP, the district requires teachers to adopt the pacing guide. The pacing guide directs teachers toward the same instructional page on the same day. Although this guide aligns with the GLCE, there are limitations. For example, the pacing guide requires accessing the alphabetic principle in isolation, whereas the GLCE delineate word recognition in the context of the reading event. Both documents additionally include literal comprehension of narrative texts, including identifying the problem, sequencing events, and sense of story. The GLCE, however, require deeper comprehension, including comparing and contrasting relationships among characters and events within and across texts and encouraging children to ask questions as they read. Although the alphabetic code and literal comprehension at state and local levels are aligned, practices outlined in the pacing guide present a mismatch with the balanced approach intended by the GLCE.

Amidst these challenges, this study aims to highlight teacher dilemmas inherent in a literacy policy that requires highly regulated local curriculum. However, there is potential for implementing Book Club as a curricular solution. This study examines Mrs. Roberts (all participants' names are pseudonyms) and her collaboration with a researcher and her student teacher to implement Book Club into her practice. Mrs. Roberts teaches first grade, and is representative of the Gladstone teachers who envisioned a need for adjusting regulated local curriculum in a manner that was more relatable to her students. In spite of her students' enhanced decoding abilities, she was concerned about the overemphasis on literal comprehension and limited opportunities for facilitating academic discourse. In a high performing Detroit Public School constrained by the pacing guide, this study was guided by the following research questions: How does a first grade teacher modify regulated curriculum to implement Book Club? How do first graders respond to participating in peer-led discussion groups?

\section{Theoretical Perspectives}

This study is situated in the body of knowledge surrounding beat the odds schools, negotiating high stakes testing pressures, Cognitive Strategy Instruction, and the Book Club Curriculum. These bodies of knowledge are brought together to inform a first grade teacher's collaboration with a researcher and student teacher to supplement the regulated curriculum with relatable literature and balanced literacy practices. Moreover, theoretical perspectives inform first graders' participation and construction of deep comprehension in peer-led discussion groups.

\section{Beat the Odds Schools}

Allington and Cunningham (2007) identify components of early reading programs in high achieving, high poverty schools. Features include a collaborative staff committed to ensuring all children can read and write and involving teachers in curricular decisions. Teachers and varied support personnel, including librarians and paraprofessionals assume a shared responsibility. In addition, teachers emphasize real reading and writing opportunities. According to Walker-Dalhouse and Risko (2007), teachers in successful urban schools make the curriculum content relevant to students. Therefore, teachers link students' cultural and linguistic experiences to skill acquisition and content knowledge. Ladson-Billings (1994) suggests students demonstrate potential, upon knowing their teachers maintain high expectations. 


\section{Negotiating High Stakes Testing Pressures and Balanced Literacy}

Culturally relevant teaching is an ingredient for success in urban schools (LadsonBillings, 1994). According to Kersten and Pardo (2007) and Valli and Buese (2007), however, teachers facing pressures to meet AYP are required to adhere closely to curriculum content aligned with high stakes testing. Because pressures have led to efforts to increase student achievement in low achieving schools or preserve high achievement in high achieving schools, NCLB legislation pushes teachers to compromise their autonomy and employ strategies that are at odds with their pedagogical beliefs.

Decoding and standardized tests that establish the purpose of reading and measurability are the focus of reading instruction (Putney, Green, Dixon, \& Kelly, 1999). Literal comprehension is employed to accommodate political pressures to raise test scores. Largely ignored is a reader's transaction with the text and aesthetic purposes for reading, in which a reader bridges prior knowledge and experience (Rosenblatt, 1978). Hence, moderate engagement in reading selections and adherence to skills and the pacing guide produce children who are not interested in reading for school related purposes (Hiebert \& Martin, 2001).

Rather than limit students to paced curriculum, Hollingworth (2007) recommends connecting existing reading units to real-world contexts, in which readers access real books and connect their home and school lives. Case studies conducted by Kersten and Pardo (2007) reveal collaborations with teachers who devised literature-based instructional strategies resembling the Book Club framework. They negotiated rigid curriculum requirements while linking elements of their best practice and placing more emphasis on the supplemental authentic literature. Thus, the researchers collaborated with teachers to prioritize the needs and interests of the children, while preserving their pedagogical beliefs and increasing student performance.

National literacy policy is guided by the National Council of Teachers of English and International Reading Association Standards for the English Language Arts (1996). Varied strategies include comprehending, interpreting, evaluating, and appreciating texts, by drawing on prior experience and interactions with other readers and writers. Students should simultaneously be guided toward word identification strategies, and understanding of textual features, including sound-letter correspondence. Skills are considered important, but in the context of actual reading and meaning making events. Similarly, literacy policy in Michigan is derived from the GLCE (2004) and informed by skills in context and interaction of reading, writing, listening and speaking. Such an enactment is embedded in the balanced approach to reading instruction, in which skills are taught in the context of reading and comprehension, a combination of skills and holistic instruction (Gove, 1983).

Center (2005) conceptualizes a balanced literacy framework during the first years of school, which should consist of phonological awareness, fluency, speaking, and listening. Learning "how to decipher print" and "understanding what print means" (p. 16) requires facilitating word recognition, while simultaneously developing listening comprehension. Both of these strategies are necessary, and cannot stand alone, to ensure the development of meaning and enjoyment (Center, 2005).

Reading acquisition and listening comprehension shape each other and are inextricably linked. Snow, Burns, and Griffin (1998) recommend a systematic balance of word recognition and meaning activities to ensure appropriate development. At the word recognition level, activities include building concepts of print through shared reading and 
word-directed activities to support the alphabetic principle and acquisition of sight word vocabulary (Snow et al., 1998). Center (2005) suggests rereading decodable readers, while supporting decoding of previously taught sounds, letters, and word families.

At the meaning level, listening comprehension activities include facilitating predictions and activating prior knowledge. Allington (2001) recommends confirmation and negation of predictions to sustain student motivation. Beck and McKeown (2001) recommend open-ended questions that encourage open-ended talk about text.

\section{Cognitive Strategy Instruction}

The Book Club framework is situated in Cognitive Strategy Instruction (CSI), a form of comprehension instruction and discourse that is integrated into reading programs in school districts, and consequently employed by classroom teachers (Handsfield \& Jimenez, 2009). CSI pedagogies include making connections (i.e., text-to-self, text-to-text, and text-to-world). Additional strategies include predicting, summarizing, questioning, clarifying, and inferencing, grounded in cognitive theories of reading (Handsfield \& Jimenez, 2009). Cognitive theories of reading postulate that activating schema enhances reading comprehension (Anderson \& Pearson, 1984; McVee, Dunsmore, \& Gavelak, 2005) and are essential to making inferences (Spiro, 1980). CSI is situated in social constructivism and Vygotskian theory (1978). Schema is informed by readers' experiences, shared by engaging in peer-led dialogue to facilitate meaning. Although classroom practices intend to be grounded in cognitive reading theories and social constructivism, a case study conducted by Handsfield and Jimenez (2009) reveals that didactic comprehension strategies persist in practice.

\section{The Book Club Curriculum}

The Book Club Curriculum is a literature-based framework that embodies the interaction of reading, writing, listening and speaking (Raphael, Florio-Ruane, Hasty \& Highfield, 2004), components manifest in state and national standards.

Open Community Share includes varied pre-reading strategies, intended to cultivate a knowledge base for the reading selection. The reading component provides access to relatable literature, including curriculum materials and supplemental stories. When instructional literature is not discussion worthy, Raphael and McMahon (1994) suggest teacher read alouds of authentic supplemental literature beyond students' decoding ability. Therefore, children construct meaning surrounding supplemental literature they ordinarily would not be able to read on their own, while being supported toward decoding curriculum literature.

Upon completing the story, teachers support the students' written reading log responses. Prompts range from identifying a favorite part, asking a question to elicit meaningful discussion, to drawing a picture. The reading logs inform peer-led Book Club discussion groups. After completing peer-led discussions, participants share outcomes with the entire group in a format termed Closing Community Share.

Tenets for discussion include the following objectives, termed "I Can" statements (Raphael et al., 2004): bring others into the discussion; build on others' ideas; respect ideas and opinions; contribute to a Book Club discussion; stay on topic when I talk. "Fish bowls" (Raphael et al., 2004) provide opportunities for students to observe their peers demonstrate a Book Club discussion. Observers determine the group's effectiveness with 
criteria from "I can" statements. When introducing Book Club, it is helpful for all classroom members to participate in fish bowl until a comfort level has been established for all students to participate simultaneously in Book Club discussion groups.

Book Club is intended to provide equitable participation opportunities. According to Raphael et al. (1992), students should be supported toward responding in a variety of ways in which their voices are added to a community where texts and their authors have been introduced. In spite of the noted benefits of Book Club, many teachers reject the concept of engaging primary students in deep discussion of literature. Although Sipe (2000) contends that primary students are capable of engaging in deep discussion of literature, teachers commonly assume otherwise. Raphael et al. (2004) additionally acknowledge teacher concerns about time constraints and perspectives that the Book Club Curriculum does not comply with standards. Therefore, Raphael et al. (2004) conceptualize Book Club Plus to assert teachers' dual obligation to provide children access to engaging literature, while meeting requirements mandated by standards. Similarly, implementation of Book Club is encouraged within the parameters of existing practices.

\section{Setting and Participants}

\section{Research Methodology}

Most Gladstone School students reside in the neighborhood, even though, Detroit is a school of choice district, in which families may select schools in any neighborhood within the city boundaries. School-wide, approximately one third of the children attend from more affluent sections of the city.

Data from this ethnographic case study was based on observations in Mrs. Robert's first grade classroom. Mrs. Roberts is European American and has taught at Gladstone School for nine years. Ms. McKay is another first grade teacher with a European American background who worked closely with Mrs. Roberts at the school. Ms. McKay opted out of participating in Book Club because of time constraints and her belief that her students did not possess the maturity to participate in peer-led discussion groups. Nevertheless, she provided insight regarding the reading curriculum.

Aside from strong administrative support, Mrs. Roberts and Ms. McKay attributed their success to closely monitoring and supporting their students' heterogeneous reading abilities as a result of sharing teaching responsibilities with their yearlong student teachers. The student teachers assumed a majority of teaching responsibilities each school day, with the exception of one day per week of required university coursework. They began the school year in September, then became lead teachers from approximately December until May.

Mrs. Robert's student teacher, Ms. Williams, was African American and enrolled in a state university located 80 miles away from the school. She was enrolled in a special Detroit team intended to prepare teachers for work in the urban context. Ms. Williams was instrumental in helping with the Book Club transition, and she assisted with the heterogeneous grouping of students in peer-led discussion groups, based upon her knowledge of whether the children would effectively interact. During the time of the study, Ms. Williams led students in word recognition activities outlined in the pacing guide. She also facilitated choral reading of decodable stories, while employing Center's (2005) and Snow's et al. (1998) recommendation for corresponding word recognition 
activities. However, the decodable stories were not related to the themed literature. In addition, she supported students toward reading the curriculum literature (known by teachers as the anthology) and facilitated teacher-led discussion of literal comprehension with the whole group.

I am a teacher educator of color, with a German and Jamaican background, at a state university in close proximity to Gladstone School. The children gladly recognized the college and welcomed my presence in the classroom. The administration welcomed me and recommended Mrs. Roberts as a teacher who would be willing to collaborate with me to attempt Book Club. Mrs. Roberts insisted the students were happy with my presence because I was a new face offering a change in the routine. During the onset of the study, I assumed a participant observer role. As the study progressed, Mrs. Roberts co-facilitated Book Clubs with me, while my role transitioned to co-teacher on Book Club days. On Book Club days we monitored the students' participation in peer-led discussion groups. During remaining days in which Ms. Williams or Mrs. Roberts enacted instruction from the mandated anthology, I assumed the role of participant observer.

\section{Data Collection Procedures}

Data were gathered one to two days per week, for approximately two hours, from February to May 2008 during the morning literacy block,. Observations of classroom practices were documented from February to March, and the Book Club transition began in April. I led the students in Book Club on six occasions, which consisted of three fish bowl discussions and three Book Club discussions. Gathered data included audiotaped peer-led discussion groups. Student reading log samples were collected and in-themoment fieldnotes were gathered to capture mandated instruction from the anthology and student interaction during read alouds and Book Club. On each Book Club day I monitored different peer-led groups to document varied representations of student voices and interactions. On days when I interacted with the students during read alouds, a research assistant gathered fieldnotes. I interviewed Mrs. Roberts and Ms. McKay at the beginning and end of the study. Interviews and peer-led discussions were audiotaped and transcribed.

\section{Data Analysis Procedures}

Data reduction corresponded with themes that emerged throughout the study. To inform this article, peer-led discussions were reduced to one fish bowl and two Book Club discussions. Integrated/Excerpt style (Emerson, Fretz \& Shaw, 1995) was implemented to analyze the data. Integrated documents include reading logs to illustrate students' written literature responses. I selected reading logs that I regarded as compelling responses to interactions with the text during read alouds. I chose to reduce field notes to document the students' participation during read alouds, in which I sought student responses that demonstrated enhanced comprehension and enthusiasm for the literature. Fieldnotes additionally captured our facilitation of Closing Community Share and other instances of our providing assistance to the students on Book Club days. Excerpts include teacher interviews to support assertions about the reading curriculum. Excerpts additionally include peer-led discussions to illustrate student participation in 
fish bowl and Book Club discussions. The reduction of excerpts was guided by compelling efforts to construct in-depth meaning.

\section{Findings}

Negotiating the Book Club Framework

Informal discussions with Mrs. Roberts and Ms. McKay during initial observations of skills-based practices revealed their struggles with meaningful comprehension of the curriculum literature because the content was not relatable to the students. Mrs. Roberts was not satisfied with the literacy policy set by the pacing guide because of limited opportunities to engage in academic discourse. Their concerns led me to inquire if they would like to implement Book Club. Ms. McKay decided against implementation, due to curricular constraints and because she thought that her students were not ready and mature enough to participate. Mrs. Roberts invited me to conduct Book Club with her students to determine what they looked like and how students would respond. During our initial interview, she stated, "I'll try them if you'll do them!" Mrs. Robert's willingness to participate initiated our collaboration toward cultivating a community of Book Club participants.

We decided that a smooth transition could be facilitated if we used the curriculum literature from the anthology, along with the relevant supplemental literature. Because of the pacing guide, we dedicated one two-hour block per week to Book Club. I agreed in my role as co-teacher, and at Mrs. Roberts' request, to read aloud the selected curriculum or supplemental literature on Book Club days.

A typical day in Mrs. Roberts' classroom began with daily journaling and author's chair. During the onset of the week, Mrs. Roberts or Ms. Williams facilitated pre-reading strategies, followed by decoding and comprehending curriculum literature. Mrs. Roberts additionally maintained a daily routine of engaging students in chanting phonics categories prior to decoding them in the decodable readers. She regularly led students in the manipulation of varying onsets, rimes and medial vowel sounds. As the following interview suggests, Mrs. Roberts was proud of her application of word recognition strategies:

Mrs. Roberts: My phonics strategies can go with program to program to program. Me: You incorporate phonics in such an exciting way.

Mrs. Roberts: Children, students who are ready to read, it gives them the tools they need to read.

Me: They are really involved with the decodables, aren't they?

Mrs. Roberts: In terms of improving and getting into it. They practice with parents each night---parents are competitive; that is refreshing.

The children excitedly responded to Mrs. Robert's practices and demonstrated their application of skills. Furthermore, Ms. Williams reinforced the phonics skills and led the students in the choral reading of the decodable readers.

On Book Club days, I reinforced the instructional curriculum literature by reading aloud and interacting with the students about the overarching theme. However, when Mrs. Roberts determined the instructional literature was not discussion worthy, I facilitated the supplemental literature as read alouds only, to link to the curriculum literature. On Book 
Club days, I conducted the read aloud, immediately following their scheduled choral reading of the decodable readers. The remainder of the week was designated for the regulated curriculum to support reading acquisition of the decodable texts and corresponding word recognition activities, along with the curriculum literature selections. On a daily basis, Mrs. Roberts concluded the literacy block with a read aloud of a novel. The children participated in self-selected reading after lunch or after completing assignments.

Facilitating Deeper Comprehension Through Read Alouds and Fish Bowls

The theme during the onset of the study was titled "Keep Trying." The curriculum literature chronicled characters who refused to give up in spite of the barriers preventing them from achieving their goals. With Mrs. Robert's approval, my first supplemental selection was Hoffman's (2005) “Amazing Grace." This selection was similar to Lobel's (1979) "The Kite," the assigned reading for the week. Mrs. Roberts regarded this story as an optimal illustration of the theme, as it exuded the notion of not giving up in order to pursue goals. "The Kite" is a story of Toad who attempts to fly a kite, but is discouraged by the birds who suggest he will never make it. With Frog's encouraging him to ignore the birds and continue trying, he is finally able to fly the kite.

"Amazing Grace" is the story of a young African American girl who wants to pursue the role of Peter Pan for the school play in spite of her classmates' insistence that she would not be able to secure the role because she is a Black girl. Her mother and Nana encourage her to pursue the role anyway. Her enthusiasm and practice render an impressive audition and gaining the part, with the support of Grace's classmates and teacher. We collaborated and decided that "Amazing Grace" would connect nicely with "The Kite" and the overall theme.

I led the read aloud with the children who gathered on the carpet. Prior to reading, I facilitated Open Community Share and asked the children to recall how the birds treated Toad in "The Kite." The children recalled the birds telling Toad he would never fly a kite and to give up. I told the children that Grace would be a lot like Toad and to pay attention to the similarities while I read. I encouraged the children to compare the characters between selections during the read aloud. In preparation for their reading logs, I prompted the children to think about their favorite part, a question to invite meaningful discussion and a picture they would like to draw to illustrate the story.

During the read aloud, I asked the children to think about similarities between Grace and Toad. Jacob expressed that Toad's desire to fly a kite was similar to Grace's desire to pursue acting. Upon arriving at the part in the story where Grace's discouraging classmates told her she couldn't take on the role, I asked them who Grace's classmates reminded them of from "The Kite." Karyn explained that Grace's classmates were like the discouraging birds. As we interacted further into the story, Grace received words of encouragement from her Nana, who took her to a ballet where the lead dancer was the daughter of Nana's friend from Trinidad. I told the children the lead of Juliet is traditionally assumed by a White dancer, which prompted some of the children to recall that Peter Pan was ordinarily portrayed by a White actor. When I encouraged the children to think about similarities with "The Kite," Jason connected Nana's encouragement to Frog's character, particularly because she inspired Grace to practice wholeheartedly. 
Upon learning about Grace winning the role of Peter Pan, many of the children suggested Grace's success was similar to Toad who was able to fly the kite.

The children responded to my use of Jamaican dialect to depict Grace's Nana. I seemingly instilled trust, upon informing that Nana reminded me of my grandmother.

Mrs. Roberts and I directed them to write in their reading logs. As they began writing in them, I was impressed with the children's questions. My expectations, however, were not as high as Mrs. Roberts', who reminded them to write more fully developed questions. For example, many students jotted the question "What if she gave up trying," to which Mrs. Roberts responded "Gave up on trying what?" Students were encouraged to elaborate on their questions. Mrs. Roberts, Ms. Williams, and I visited various students and provided support in accordance with their varying abilities. Regardless of ability, we encouraged the children to devise sophisticated questions.

Jason's reading log illustrates his response to Mrs. Roberts' request to write more than "What if she gave up trying?" with his question (Figure 1). His noted favorite part provided his acknowledgement that Grace could do anything, contrary to her classmates' initial reactions that she could not pursue this role because of her gender.

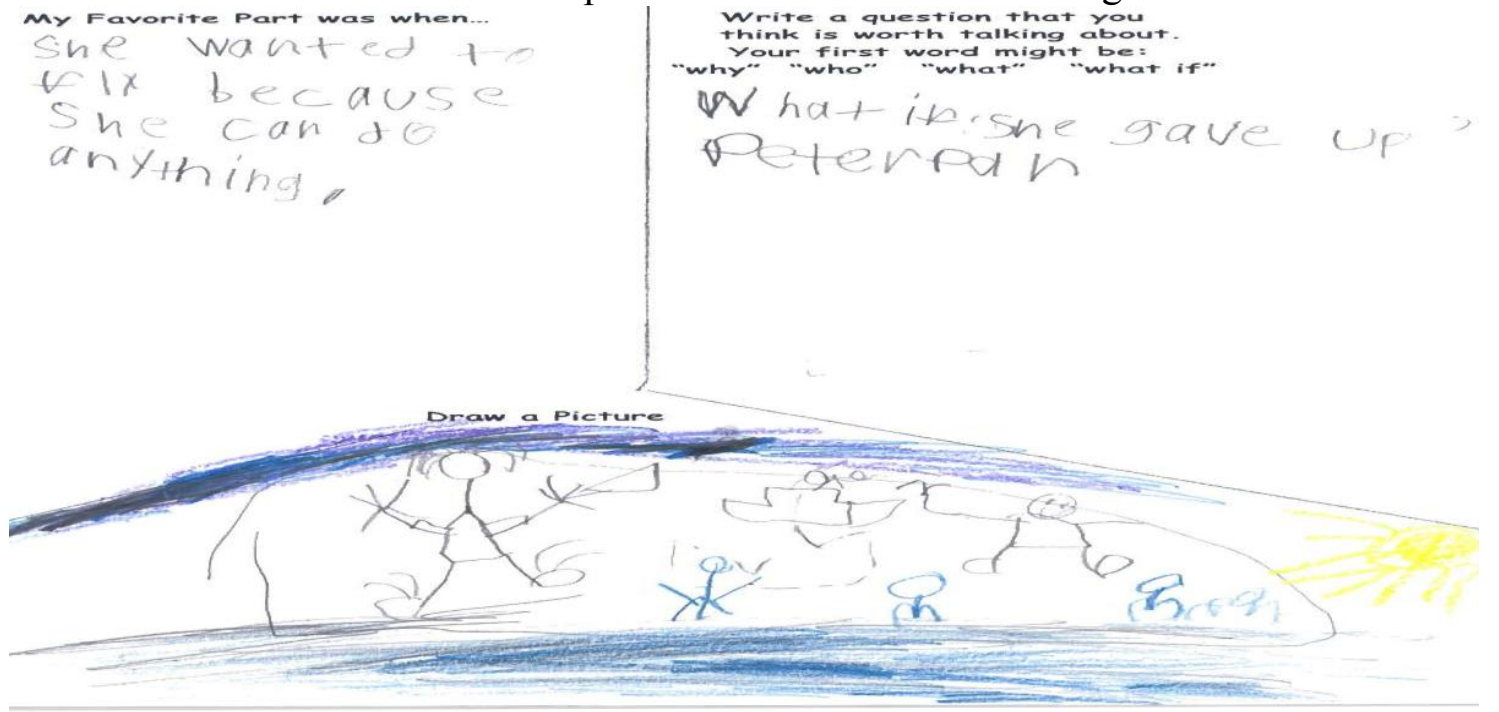

Figure 1. My favorite part was when she wanted to fly because she can do anything/What if she gave up being Peter Pan?

Upon completion of the reading logs, we gathered the students on the carpet and discussed the I Can statements to develop a schema for the turn-taking rules and ensure effective academic discourse. One demonstration group of five students participated in a fish bowl (Raphael et al., 2004).

Fish bowl students included Brent, Jason, Jacob, Karyn, and Michelle. They were talkative and built on each others' ideas:

Brent: Her mom would be mad if she gave up.

Jason: What if her Nana wanted to give up?

Karyn: Then she wouldn't try.

Jacob: She would forget about it and try a new talent. She'd keep on trying. 
Brent: She'd want to surprise her if she made the part. If she wanted to be a girl part, what would her Nana say?

Karyn: She could be Wendy.

Jason: Everybody voted for her.

Michelle: Because she knew all the parts. How come she can't be Wendy?

Jason: She has no powers and can't fly.

Brent: She wanted to be Peter Pan because she can fly.

Jacob: She can fly or she can be Captain Hook.

This excerpt illustrates that the reading logs were an initial springboard for discussion, but contributions were improvisational because many of their spoken ideas did not appear in their reading logs. To illustrate, Jason responded to Brent by asking a question that differed from the question he wrote in his reading log (Figure 1). Brent's comment about the reaction from Grace's mother may have prompted Jason to adjust his "what if she gave up on being Peter Pan" question to "What if Nana wanted her to give up." In addition, his idea may have been initiated from his contribution about Nana's enthusiasm in relation to Toad during the read aloud. The children's understanding about Nana's enthusiasm in the story led to their discussion of how Grace might have responded if she did not have the encouragement of her caregivers. It is possible that responses about Nana were influenced by my comments about my grandmother. Perhaps I instilled a sense of trust and closeness to the characters. Open-ended questions instilled open-ended responses that Beck and McKeown (2001) suggest for sustaining deep comprehension.

Michelle's suggestion about Grace taking Wendy's role prompted Jason to raise a point about Grace being able to do anything from his reading log. However, he expressed his idea in different terms when he suggested that Grace would not be interested in pursuing Wendy's character because she did not have Peter Pan's powers. The overall discussion conveyed the group's familiarity with Peter Pan, in conjunction with Grace's determination and encouragement to pursue the role in spite of being discouraged by her peers. Participants transacted with the text and bridged their prior knowledge to enhance comprehension (Anderson \& Pearson, 1984; McVee et al., 2000; Rosenblatt, 1978). In addition, their enactment of text-to-text connections during the read aloud and fish bowl aligns with tenets of CSI (Handsfield \& Jimenez, 2009).

Mrs. Roberts and Ms. Williams were impressed with Brent's participation. As the discussion progressed, they looked at each other and at me in a manner that conveyed their excitement at the discussion. Brent's equitable participation was significant during the fish bowl because he did not participate during the read aloud discussion, nor did he typically participate during class.

Mrs. Roberts led Closing Community Share and invited the students to discuss what went well. Tony noted that the students listened to each other. Sheila suggested that the participants were smart, listened to and respected each other. Their responses indicate they readily understood I Can statements (Raphael et al., 2004). Kyle also mentioned that they kept going without relying on their papers. Mrs. Roberts praised the students for their specific comments. Moreover, she affirmed their perspective that Peter Pan was a more exciting character than Wendy. 
After the morning session, Mrs. Roberts informally told me the fish bowl was a turning point for Brent because he blossomed for the first time. She was concerned that he rarely spoke in school and attributed his difficulties to his unstable home life. According to Mrs. Roberts, peer-led discussions were a missing ingredient in the curriculum and the children did not have opportunities to articulate ideas beyond the text.

The existing prompts in the curriculum did not provide opportunities for students to appropriate the text from multiple perspectives. For example, the directives in the curriculum for "The Kite" invited students to identify why Toad kept wanting to give up and why Frog wanted him to keep trying, which could be identified directly in the text. Although there were prompts connecting the selection with personal experiences in reaching a goal, Mrs. Roberts appreciated the improvisational peer-led discussion and students' eagerness to participate.

During a formal interview, she and Mrs. McKay noted the dilemmas of working with the existing reading curriculum materials:

Me: So what are some things that you have done to make the anthology (reading curriculum) doable?

Mrs. Roberts: The anthology is not just...you know you have to do it, but there are things you can do to make it doable and workable for you.

Ms. McKay: The content is not appropriate to our population.

Mrs. Roberts: The way the anthology is set up in themes. Everything is the anthology. It doesn't give you space to do anything else. The first year everyone taught it to a tee and as time has gone on I think everyone makes it work.

Ms. McKay: They have a writing workbook that is too hard. They are taking children who have never written other than pictures and teacher made sentences.

Mrs. Roberts: We use the anthology to answer the questions. It is very difficult for them. The workbooks are skills based but they don't bring in skills from the anthologies. The grammar is in isolation. This is why I like the student participation in the book clubs we've been doing.

Ms. McKay: And not bringing in the actual selection. There are no phonics, and the parts of comprehension are not related to text. I've seen the connections to comprehension with our previous anthology.

This excerpt reveals that the existing comprehension focus mandated by the local literacy policy was difficult for the students to grasp. The children experienced difficulty relating to the content, which hampered their interest in reading for school related purposes (Hiebert \& Martin, 2001). With the exception of the selection, Jones' (1991) "Matthew and Tilly," none of the curriculum selections in the theme included African American characters. Freeman and Freeman (2004) suggest that students' comprehension is heightened upon exposure to culturally relevant texts in which children can see themselves accurately depicted. It is possible to surmise heightened interest in Grace because they could identify with a talented Black character determined to exceed her peers' expectations. Mrs. Roberts was excited about fish bowls and arranged for me to continue the read alouds as a co-teacher. We agreed to collaborate and support the students with their reading logs. We collaborated to facilitate the Book Club discussions with Ms. Williams' support and Mrs. Roberts led the Closing Community Share 
component. Upon rotating all of the children in and out of the fish bowls for three weeks, we decided the children had a good grasp of the turn-taking rules and were ready to participate in the simultaneous Book Club groups.

\section{Implementing Book Club Discussion Groups}

The transition to Book Club groups began with the next theme, "Being Afraid". The curriculum and supplemental literature selections included characters who experienced fear. We collaborated and divided the students into three groups of six students so that we could monitor the students' participation..

Steig's (1969) "Sylvester and the Magic Pebble" was a supplemental text. As the Book Club discussions progressed, Mrs. Roberts expressed concerns about the students raising their hands to participate and acknowledged their familiarity with raising their hand during the whole group discussions. However, she helped the children understand how small groups were intended for conversation with each other and to build on previous ideas when appropriate. In addition, students were reminded to listen to each other and to fully respond to the questions. This reminder was necessary because since the transition, they exhibited a tendency to not listen to each others' questions, a stark contrast from the fish bowl groups. All of us paid attention to turn-taking behaviors as we continued with the peer-led discussions.

"Sylvester and the Magic Pebble" is about a young donkey named Sylvester who is enticed by a magic pebble that grants him wishes. Upon encountering a lion, he panics and wishes himself into a rock, only to find that he cannot wish himself back if he cannot place the pebble in his hand. What elicits fear is the fact that his parents are unable to find him for several months.

During Open Community Share, I invited the students to provide examples of a time they were lost from their parents or caregivers. Students discussed losing family members in public places. Upon being asked how they felt, the children told me they were sad. Sheila, however, claimed her mother panics when she loses anything. To encourage emotions beyond being sad, we examined the cover for predictions and identified Sylvester's parents who looked extremely worried. Sylvester himself was not on the cover, so the students predicted that his parents were frantically searching for him.

During the read aloud, Natalie noticed that Sylvester used the pebble to make wishes come true, upon wishing for the rain to stop and the sun to shine. Upon seeing the lion, Jacob thought he should wish to be invisible, for the lion to disappear, or be safe at home. Several children questioned his wish to be a rock, but reasoned that he could not think clearly in his panicked state. As the story progressed, Natalie immediately pointed to the illustration that shifted from day to night. I contrasted Sylvester's being lost for several hours to being lost for just 10 minutes, which feels like forever when one is panicking. As the story progressed, the students' fears set in when they noticed Sylvester could not reach the magic pebble. Natalie suggested he should have wished to be a rock with arms and legs and Jason noted he should have wished to be a talking rock. As Sylvester's parents searched for him, Natalie pointed out the illustration of the leaves on the ground and confirmed the prediction from the cover. Students panicked upon recognizing the extended length of time Sylvester was lost. The arrival of winter prompted the students to become more frightened. When spring arrived, Jason became frightened because he predicted his parents would never find him. Jason became relieved 
when Sylvester's parents arrived at the rock one day. Sighs of relief emerged when Sylvester's father placed the magic pebble on the rock and Sylvester wished himself with his family again. Student motivation was enhanced, as the predictions were confirmed and negated, as Allington (2001) recommends.

The discussion and interaction during the read aloud led to reading log responses that pondered whether he should have wished differently or if he was never found, as is evident in Dan's reading log (Figure 2). His illustration represents the flaming red magic pebble, juxtaposed in close proximity to the rock, but still too far for Sylvester to wish his way home.

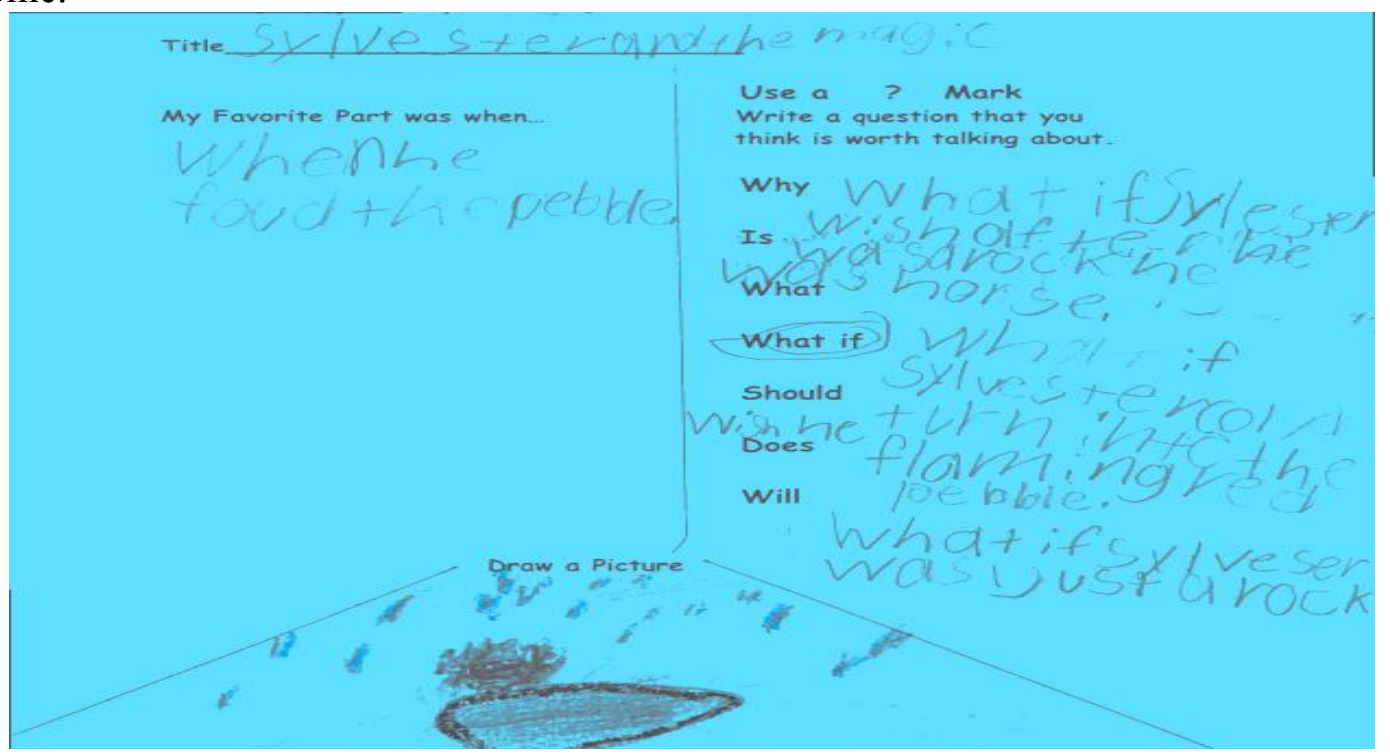

Figure 2. My favorite part was when he found the pebble... What if Sylvester could turn into the flaming red pebble?...

Prior to Book Club groups, we revisited the I Can statements to develop a schema for turn-taking rules and noted students' not raising hands to participate. In addition, we reminded the students to attempt to answer the questions. Participants in my group included Natalie, Dan, Sheila, Jacob, Bethany and Darren. Natalie eagerly inquired about choosing her peers to participate to alleviate the pattern of raising hands.

Natalie: I pick Daniel

Dan: What if Sylvester could wish he turn into the flaming red pebble?

Sheila: He couldn't turn himself back because he was a rock and the rock couldn't talk.

Darren: Or he could have used (the pebble) if he had feet, he could have used his feet.

Jacob: He could have wished he was a talking pebble so he could wish himself back.

Sheila: He could have turned into a big pebble. I have a question. What if Sylvester was never found?

Bethany: If Sylvester was never found, his parents they would keep looking for him. 
This excerpt reveals the complexity of the "what if" questions, which required the children to consider possibilities within the frame of Sylvester's circumstances, but beyond the text. Particularly salient was Dan's question, which prompted the group to ponder over what Sylvester could have done differently to avoid getting lost. Speaking turns reveal multiple attempts to respond to the initial question, presenting an indicator that the children were becoming accustomed to listening to each other. Sheila's question coincided with the read aloud discussion because students were fearful Sylvester would never be found. Bethany's response demonstrates her awareness of the parent's commitment to finding Sylvester, and presents an example of linking the text with her personal experiences, consistent with tenets of CSI (Handsfield \& Jimenez, 2009).

During Closing Community Share, all groups praised themselves for not raising their hands in order to participate, for listening to each other, and for building on other's ideas. The children displayed an enhanced schema for turn-taking rules. Mrs. Roberts commended the students for being insightful in responding to each other and encouraged them to continue for upcoming Book Club groups. For improvement, she encouraged the children to work on staying on topic and elaborating on each other's ideas.

Osborne's (1982) "My Brother Is Afraid of Just About Everything" was an anthology text that was utilized to support reading acquisition and listening comprehension support, in alignment with Center (2005). The premise for the story is an older sister who cannot understand her younger brother's fear of everything. Mrs. Roberts and I collaborated about the timing for introducing the selection, since I normally facilitated read alouds of supplemental texts after pre-reading strategies and initial reading acquisition support of anthology selections. We decided I should introduce the story to the children.

During Open Community Share, I invited the children to predict the brother's fears, which generated ideas of being afraid of the dark, to fears of dogs. The children mentioned younger siblings' fears, in addition to their own. During the read aloud, Darious claimed he understood the little boy's fear of the vacuum cleaner. He was likely responding to his peers' surprise about such a fear, in agreement with the older sister in the story. Near the end of the story, a twist emerged as the younger brother played with a dog while his older sister was clearly afraid. Miranda could not understand the older sister's fear.

Darious informed about his mother's fear of vacuums as a child as he worked on his reading log. His classmates' responses likely inspired his question (Figure 3 ) because he produced a personal understanding for this fear, in alignment with CSI (Handsfield \& Jimenez, 2009). His response to the favorite part prompt (Figure 3) was likely inspired by the unexpected fear expressed by the older sister during the read aloud. 


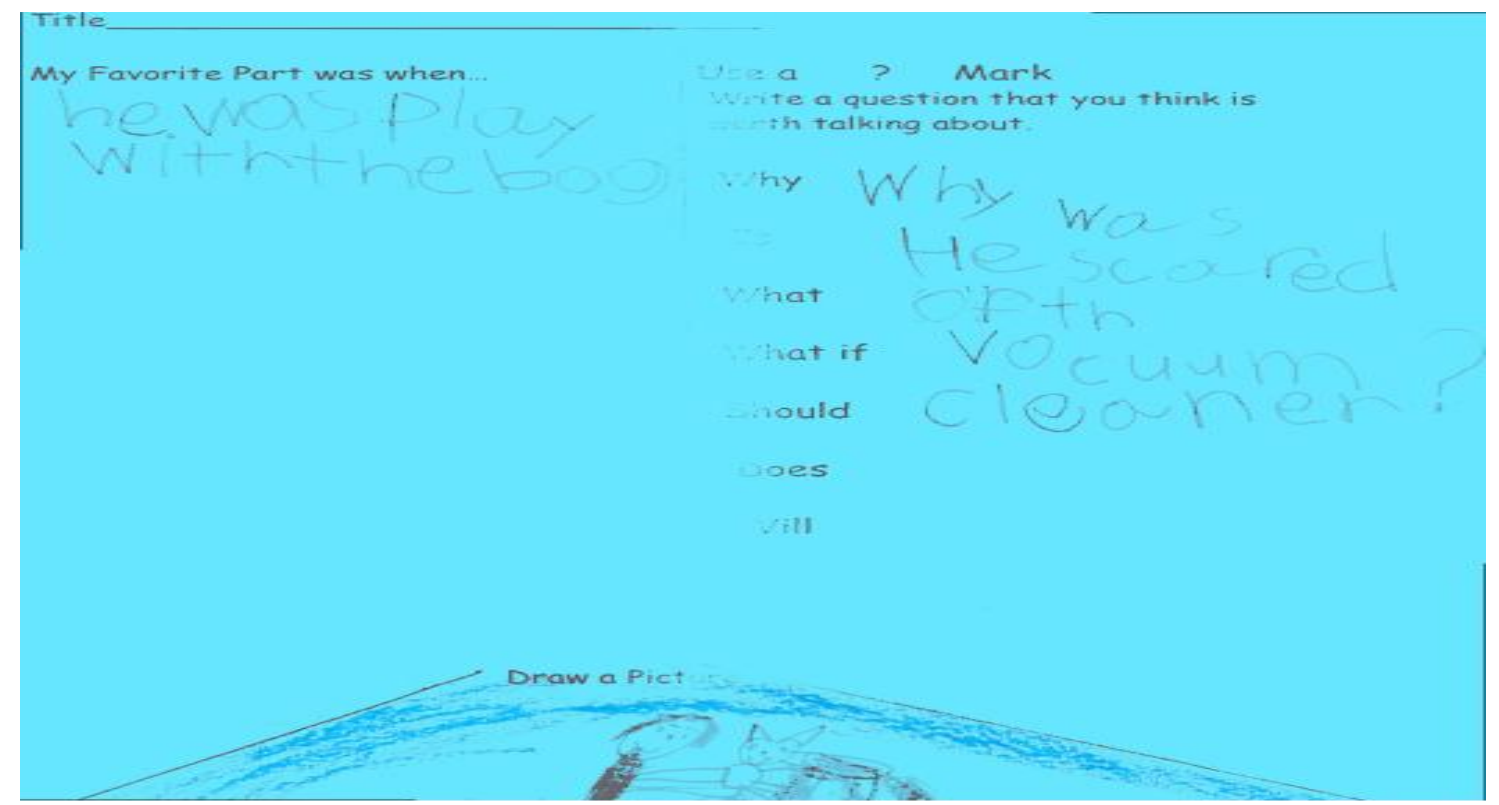

Figure 3. My favorite part was when he was playing with the dog; Why was he scared of the vacuum cleaner?

Prior to grouping the children, I reminded them about Mrs. Robert's suggestions to stay on topic and elaborate on their peers' ideas to support their schema for turn-taking rules. I also informed about listening and responding to each others' questions, prior to moving on to new ones. The following excerpt reveals an attempt to respond to our directives:

Ariel: Why is she afraid of the dog?

Darious: A lot of people are afraid of dogs.

Jacob: They have sharp teeth.

Jason: Everybody's afraid of something. Because dogs like meat.

Miranda: When dogs bark, they make a lot of scary sounds.

Darious: Why would the brother be afraid of a vacuum?

Jason: Because it sounded like a monster.

Jacob: Everybody has to be afraid of something.

Darious: My mother was afraid of the vacuum when she was little.

Ariel's initial question generated responses from all group members, which illustrates efforts to remain on topic and participate equitably. Darious' question somehow did not garner responses from the girls in the group. However, the boys elaborated on why a vacuum cleaner might elicit fear. Moreover, their responses demonstrate tenets of CSI (Handsfield \& Jimenez, 2009), for they contributed their personal understanding to rationalize the older sister's fear of dogs and the little boy's fear of vacuum cleaners. Mrs. Roberts and I commended the children for building on others' ideas and taking the time to listen and respond to each other.

The remainder of the week, the students reread the story, completed in-the-text responses and sequencing activities, along with the choral reading of the decodable readers, for an overall application similar to Center's (2005) suggestions for balanced 
literacy. The following interview excerpt illustrates Mrs. Robert's perspective about her students' enhanced participation in the peer-led discussions about text, within the curriculum parameters:

My students now have a toolbox for participating in academic discussion about the selections they read. I was confident about their strong decoding skills, but struggled with a curriculum that was not relatable to my population. I can make this work. I am more confident about adjusting the curriculum and integrating discussion groups to enrich comprehension, listening and speaking skills.

Ultimately, our on-going collaboration instilled a sense of confidence that it was possible to facilitate the academic discourse that was missing in the district-sanctioned curriculum that prioritized word recognition strategies. I provided an instructional model to follow, which enabled her to rationalize the approach.

\section{Limitations of the Paced Curriculum}

Mrs. Roberts' children demonstrated complex comprehension processes through the use of oral language and relatable literature. However, Ms. McKay's decision to not participate poses limitations for implementing Book Club in a climate of the paced curriculum. The perception that high stakes testing pressures posits no time for implementing a literature-based curriculum persists in the field (Raphael et al., 2004). In addition, Ms. McKay's concerns about her students' readiness led me to examine their participation. On numerous occasions in her classroom, her student teacher led the children in didactic comprehension practices that were dictated by the pacing guide. Students attempted deeper thinking about texts during teacher-led practices, but time constraints rendered it was not possible to facilitate equitable participation. Moreover, there was little time to investigate more complex ideas beyond the teacher's manual. The following year, many of Ms. McKay's students were enrolled in a second grade Book Club classroom that I helped facilitate. The students demonstrated the readiness to participate. During that process, they displayed deep engagement with texts, which was not evident during the previous year.

The collaborative efforts enacted to implement Book Club into Mrs. Robert's class demonstrates the possibility of adjusting practices to accommodate the framework, without compromising curriculum requirements. Implementation requires a willingness to collaborate and take risks. The following interview excerpt demonstrates Mrs. Robert's willingness to consider continuing Book Club in her practice, but only with the support of a student teacher:

I would be willing to continue using Book Club, but only with the assistance of a student teacher. Some (peer-led) groups can manage without being closely monitored, but my concern is that I need more than one adult to monitor behavioral issues.

Mrs. Robert's perspective is consistent with Allington and Cunningham's (2007) claim about effective literacy programs requiring shared responsibility with support personnel. Although the support of a student teacher is not the same as a librarian or 
paraprofessional, Mrs. Robert's case is sufficient in an underserved school. I did not work with Mrs. Roberts the following year, as she insisted I collaborate with the second grade teacher who enrolled most of the students from this study. When I followed up with her the following year, she informed that she negotiated Book Club with her student teacher.

Another limitation is employing Book Club more than one day per week, due to curricular constraints. The U.S. Department of Education has called for more stringent standards. Since this study, a school's requirement of 70 percent proficiency at third grade to make AYP has risen to 78 percent in 2011 (Michigan Department of Education, 2011). Consequently, fewer schools in Michigan have made AYP, which renders more pressure to abide by the rigid district-sanctioned curriculum than ever before. Although it is possible to implement Book Club components, existing pressures pose more challenges for implementation of literature-based practices beyond one literacy block.

\section{Conclusion}

Mrs. Roberts provided systematic access to word recognition strategies and literal comprehension in a climate of paced curriculum. Although achievement at Gladstone School surpassed state averages, the district-sanctioned pacing guide did not provide balanced literacy instruction, within the frame of policy shaped by state and national standards. Her concerns about deeper comprehension, irrelevant content, and student opportunities to communicate led to our collaboration. Mrs. Robert's recognition of adjusting existing practices and gradual transition was manifest in openness to new ideas, and her willingness to collaborate with me and Ms. Williams.

We implemented Book Club one day per week and decided about the curricular and supplemental literature choices to elicit meaningful discussion. We facilitated peerled discussion groups to enhance comprehension, listening and speaking skills. Students were enthusiastic about the read alouds. They constructed multiple interpretations, personal connections, and provided critical questions and responses to the literature. While developing a schema for academic discourse, the students were cognizant of the turn-taking rules. Students' attempts at responding to each others' questions facilitated deep comprehension and mediation of complex ideas. Mrs. Roberts commended her students' participation and invited students to self-assess their participation. Similarly, she encouraged the students to consider improving for upcoming discussions. Weekly Book Club groups made it possible to connect balanced literacy practices situated in the state regulated curriculum, while fulfilling the pacing guide requirements. Our collaboration revealed the possibility of connecting the rigid reading curriculum to real world contexts (Hollingworth, 2007). Students responded meaningfully, upon accessing the supplemental authentic literature (Kersten \& Pardo, 2007) and displayed varying aspects of CSI (Handsfield \& Jimenez, 2009). They demonstrated readiness for academic discourse about literature. Students were provided a balancing act between word recognition activities and listening comprehension (Center, 2005).

Low performing and aspiring schools can benefit from this study, for it illustrates a teacher's willingness to collaborate, take risks, and provide youngsters access to indepth comprehension. Just as Mrs. Roberts determined her students could enhance their Book Club participation, she surmised existing curricular practices could be improved. She accomplished that, without compromising the local district regulated curriculum, and, as Raphael et al. (2004) contend, within the parameters of her existing practice. 


\section{References}

Allington, R.L., \& Cunningham, P.M. (2007). Schools that work: Where all children read and write (3rd ed.). Boston, MA: Allyn and Bacon.

Allington, R.L. (2001). What really matters for struggling readers: Designing researchbased programs. New York, NY: Longman.

Anderson, R., \& Pearson, P.D. (1984). A schema-theoretic view of basic processes in reading comprehension. In P.D. Pearson, R. Barr, M.L. Kamil, \& P.B. Mosenthal (Eds.), Handbook of reading research (pp. 37-55). New York, NY: Longman.

Beck, I.L., \& McKeown, M.G. (2001). Text talk: Capturing the benefits of read-aloud experiences for young children. The Reading Teacher, 55(1), 10-20.

Center, Y. (2005). Beginning reading: A balanced approach to teaching literacy during the first three years of school. New York, NY: Continuing International Publishing Group.

Emerson, R.M., Fretz, R.I., \& Shaw, L.L. (1995). Writing ethnographic fieldnotes. Chicago, IL: The University of Chicago Press.

Freeman, Y., \& Freeman, D. (2004). Connecting students to culturally relevant texts. Talking Points, 15(2), 7-11.

Gove, M. (1983). Clarifying teachers' beliefs about reading. The Reading Teacher, 37(3), 261-268.

Grade Level Content Expectations. (2004). Retrieved September 1, 2010, from http://www.michigan.gov/documents/ELAGLCE_140483 7.pdf

Handsfield, L.A., \& Jimenez, R.T. (2009). Cognition and misrecognition: A Bourdieuian analysis of cognitive strategy instruction in a linguistically and culturally diverse classrooms. Journal of Literacy Research, 41(2), 151-195.

Hiebert, E.H., \& Martin, L.A. (2001). The texts of beginning reading instruction. In R. Barr, M.L. Kamil, P.B. Mosenthal, \& P.D. Pearson. (Eds.). Handbook of reading research (Vol.2, pp. 361-375). Mahwah, NJ: Lawrence Erlbaum Associates.

Hoffman, M. (2005). Amazing grace. New York, NY: Dial Books.

Hollingworth, L. (2007). Five ways to prepare for standardized tests without sacrificing best practice. The Reading Teacher, 61(4), 339-342.

Jones, R.C. (1991). Matthew and Tilly. New York, NY: Puffin Books.

Kersten, J., \& Pardo, L.S. (2007). Finessing and hybridizing: Innovative literacy practices in Reading First classrooms. The Reading Teacher, 61(2). 146-154.

Ladson-Billings, G. (1994). The Dreamkeepers: Successful teaching for African American students. San Francisco, CA: Jossey-Bass Publishers.

Lobel, A. (1979). The kite. New York, NY: HarperCollins Publishers.

McVee, M., Dunsmore, K., \& Gavelak, J.R. (2005). Schema theory revisited. Review of Educational Research, 75(4), 531-566.

Michigan Department of Education. (2011). 2010-2011 Guide to reading the Michigan school report cards. Retrieved on December 15, 2011 from https://oeaa.mi.us/ayp/Docs/Guide to reading schoolreportcards.pdf.

National Council of Teachers of English and International Reading Association.(1996). Standards for the English language arts. Urbana, IL, \& Newark, DE: Authors.

Osborne, L. (1982). My brother is afraid of just about everything. Park Ridge, IL: Albert Whitman \& Company. 
Putney, L.G., Green, J.L., Dixon, C.N., \& Kelly, G.J. (1999). Evolution of qualitative research methodology: Looking beyond defense to possibilities. Reading Research Quarterly, 34(3), 368-377.

Raphael, T.E., McMahon, S., Goatley, V.J., Bentley, J., Boyd, F. Pardo, L. \& Woodman, D. (1992). Research directions: Literature discussion in the reading program. Language Arts, 69(1), 54-61.

Raphael, T.E. \& McMahon, S.I. (1994). Book Club: An alternative framework for reading instruction. The Reading Teacher, 48(2), 102-115.

Raphael, T.E., Florio-Ruane, S, George, M., Hasty, N., \& Highfield, K. (2004). Book club plus! A literacy framework for the primary grades. Lawrence, MA: Small Planet Communications.

Rosenblatt, L. (1978). The reader, the text, and the poem: The transactional theory of the literary work. Carbondale, IL: Southern Illinois University Press.

Sipe, L. (2000). The construction of literary understanding by first and second graders in oral responses to picture storybook readalouds. Reading Research Quarterly, 35(2), 252-275.

Snow, C.E., Burns, M.S., \& Griffin, P. (Eds.) (1998). Preventing reading difficulties in young children. National Research Council Washington, DC: National Academic Press.

Spiro, R. (1980). Constructive process in prose comprehension and recall. In R. Spiro, B.C. Bruce, \& W.F. Brewer (Eds.), Theoretical issues in reading comprehension (pp. 245-278). Hillsdale, NJ: Lawrence Erlbaum Associates.

Steig, W. (1969). Sylvester and the magic pebble. New York, NY: Aladdin Books.

Valli, L., \& Buese, D. (2007). The changing roles of teachers in an era of high \& stakes accountability. American Educational Research Journal, 44(3), 519-558.

Vygotsky, L.S. (1978). Mind in society: The development of higher psychological processes. Cambridge, MA: Harvard University Press.

Walker-Dalhouse, D., \& Risko, V.J. (2007). Learning from literacy successes in high achieving urban schools. The Reading Teacher, 61(5), 422-425.

Wilson, W.J. (1996). When work disappears: The world of the urban poor. New York, NY: Vintage Books.

\section{Author Biography}

K. Dara Hill is Assistant Professor of Reading and Language Arts at the University of Michigan-Dearborn. Her research interests include high performing urban schools and pre-service teacher dispositions for urban contexts and culturally responsive reading pedagogy. 